\title{
SISTEM INFORMASI PERAMALAN JUMLAH PENGUNJUNG MENGGUNAKAN METODE DOUBLE EXPONENTIAL SMOOTHING (STUDI KASUS BODY GYM KOTA MALANG)
}

\author{
Eka Larasati Amalia ${ }^{1}$, Agung Nugroho Pramudhita ${ }^{2}$, Muhammad Hafidz Ilham Priambudi ${ }^{3}$ \\ Program Studi Teknik Informatika, Jurusan Teknologi Informasi, Politeknik Negeri Malang \\ Jl. Soekarno Hatta No. 9 Malang 65141, Indonesia \\ 1eka.larasati@polinema.ac.id, ${ }^{2}$ agung.pramudhita@polinema.ac.id, ${ }^{3}$ mhafidzilham@gmail.com
}

\begin{abstract}
Abstrak
Sistem informasi ini digunakan untuk melakukan kegiatan sehari-hari di Body Gym Malang dimana prosesnya yang saat ini masih menggunakan cara manual dan memerlukan waktu yang membuatnya tidak efisien. Hal ini yang menjadikan diperlukannya sistem yang mampu mengolah data dengan komputerisasi. Dari permasalahan diatas, penulis membuat sebuah sistem informasi dalam bentuk website yang memiliki fitur untuk mengatur keseluruhan informasi di website tersebut.

Sistem ini diharapkan dapat membuat pemilik dan karyawan tempat fitness tersebut agar bisa lebih efektif untuk melakukan kegiatan sehari-hari. Sistem informasi ini memiliki fitur untuk pencatatan keuangan, menunjukkan grafik pendapatan, pencatatan jumlah pengunjung, request PT, dan report untuk data. Sistem informasi ini juga dilengkapi fitur utama, yaitu dapat meramalkan jumlah pengunjung fitness, zumba, dan aerobik menggunakan metode Double Exponential Smoothing dan dapat mengeluarkan rekomendasi untuk pemilik tempat gym. Data yang digunakan untuk meramalkan jumlah pengunjung fitness yaitu data aktual dari tahun 2015 hingga 2019.

Dari hasil perhitungan data pengunjung fitness menggunakan konstanta 0,06 dihasilkan hasil peramalan sebanyak 1879 orang pengunjung di Bulan Desember 2019 dimana hasil tersebut merupakan hasil yang paling baik setelah dihitung dengan error MAPE sebesar 11,64\% dan dengan akurasi ketepatan sebesar 88,36\%. Sedangkan untuk fitur kegiatan yang lainnya, aplikasi website ini sudah memiliki fitur yang cukup lengkap dan sesuai dengan fungsinya setelah dilakukan pengujian sistem dan user untuk melakukan kegiatan sehari-hari dengan terkomputerisasi.
\end{abstract}

Kata kunci : sistem informasi, tempat fitness, peramalan, double exponential smoothing.

\section{Pendahuluan}

Sistem Informasi merupakan hal yang terpenting dalam suatu tempat usaha. Dengan adanya sistem informasi, maka suatu organisasi atau tempat usaha dapat menjamin informasi yang terdapat di sistem tersebut untuk mengambil keputusan berdasarkan informasi tersebut. Oleh karena itu, seiring perkembangan teknologi maka kebutuhan sistem informasi memberikan manfaat yang sangat banyak seperti penyajian informasi yang dibutuhkan dapat diperoleh secara cepat, tepat, dan lengkap tanpa harus melalui proses pencarian informasi yang sulit (Fitri \& Fatmawati, 2019).

Saat ini di tempat fitness Body Gym Malang belum memiliki sistem informasi untuk melakukan pendataan, sekarang di lapangan masih menggunakan buku tulis untuk mencatat nama pengunjung yang datang setiap harinya. Tata letak tempat penyimpanan juga menjadi kendala yang berakibat dapat kehilangannya buku untuk pencatatan. Website ini juga dapat berguna sebagai pengganti buku dalam kegiatan pencatatan pengunjung setiap harinya agar mempermudah pendataan dan dapat mengurangi penggunaan kertas. Untuk di sisi pihak pemilik tempat fitness, mereka tidak dapat melakukan pemantauan langsung jumlah pengunjung yang datang dari waktu ke waktu.

Terdapat banyak manfaat dalam menggunakan sistem informasi berbasi website dalam dunia bisnis, yaitu dapat menghemat waktu dan biaya karena proses bisnis dilakukan secara elektronik tidak menggunakan kertas dan mudah diakses dimanapun dan kapanpun, serta mudah dikelola dan diperbarui informasinya (Rahayu \& Amrozi, 2019).

Dari permasalahan diatas penulis ingin membuat sebuah sistem informasi dalam bentuk website yang memiliki fitur admin yang dapat mengatur keseluruhan informasi website dan melakukan peramalan jumlah pengunjung di waktu mendatang. Sedangkan untuk di sisi pengguna website ini dapat digunakan untuk melihat informasi apa saja yang ada pada tempat tersebut.

Sistem informasi ini akan dilengkapi dengan sistem peramalan jumlah pengunjung yang dapat digunakan oleh pemilik agar dapat membuat sebuah 
keputusan yang lebih tepat dan dapat menambah kinerja karyawan untuk melakukan pelayanan kepada pelanggan agar lebih efektif. Sistem peramalan di dalam website ini menggunakan metode Double Exponential Smoothing. Metode Double Exponential Smoothing memiliki kelebihan dapat menggunakan data yang relatif sedikit, parameter yang digunakan lebih sedikit dan mudah dalam pengelolaan data dalam meramalkan.

\section{Relevansi Penelitian}

Jurnal hasil penelitian (Rahayu \& Amrozi, 2019) menunjukkan bahwa rancangan sistem informasi fasilitas fitness center dapat digunakan untuk pendaftaran keanggotaan secara online serta untuk memudahkan anggota mengetahui informasi jadwal pelaksanaan fitness. Kesimpulan yang dapat diambil dari penelitian tersebut adalah hasil aplikasi berbasis website tersebut dapat digunakan untuk pendaftaran keanggotaan, penjadwalan pelaksanaan fitness, serta pengelolaan data personal trainer untuk memudahkan anggota mengertahui informasi jadwal pelaksanaan kegiatan.

Jurnal penelitian (Imbar \& Andreas, 2010) menunjukkan sistem dapat mengolah data lebih efisien dan mudah dalam pencarian data, sehingga dapat terhindar dari kesalahan yang dapat terjadi jika dilakukan dengan cara manual. Lalu fitur laporan dapat menjadi pertimbangan bagi pihak toko untuk lebih dapat memaksimalkan pendapatan per tahunnya dan membuat perhitungan data yang lebih jelas. Sedangkan untuk fitur peramalan, dapat membuat pihak toko lebih mudah dalam melakukan proses pengadaan barang.

Hasil penelitian (Hermawan \& Purwanto, 2019) menunjukkan sistem tersebut telah mampu melakukan perhitungan dengan metode Double Exponential Smoothing yang sesuai dengan perhitungan manual dan menghasilkan tingkat kesalahan prediksi sebesar 8,68\% atau memiliki tingkat akurasi sebesar $9,11 \%$.

\section{Metodologi Penelitian}

\subsection{Pengumpulan Data}

Data yang diperoleh merupakan data dari Body Gym Kota Malang berupa data jumlah pengunjung tempat fitness bulan Januari 2015 hingga bulan November 2019. Data tersebut diperoleh langsung dari data absensi pengunjung tempat fitness yang disederhanakan dari data per-hari menjadi data per-bulan untuk dilakukan perhitungan peramalan jumlah pengunjung di periode yang berikutnya.

Berikut ini adalah sebagian data data jumlah pengunjung tempat fitness tahun 2015 yang dapat dilihat pada Tabel 1 dibawah ini :
Tabel 1. Data Jumlah Pengunjung

\begin{tabular}{|c|c|l|c|}
\hline No & Tahun & Bulan & Jumlah \\
\hline 1 & 2015 & Januari & 1501 \\
\hline 2 & 2015 & Februari & 1382 \\
\hline 3 & 2015 & Maret & 1611 \\
\hline 4 & 2015 & April & 1371 \\
\hline 5 & 2015 & Mei & 1310 \\
\hline 6 & 2015 & Juni & 1659 \\
\hline 7 & 2015 & Juli & 1199 \\
\hline 8 & 2015 & Agustus & 1556 \\
\hline 9 & 2015 & September & 1411 \\
\hline 10 & 2015 & Oktober & 1636 \\
\hline 11 & 2015 & November & 1592 \\
\hline 12 & 2015 & Desember & 1688 \\
\hline
\end{tabular}

Berikut ini adalah analisis kebutuhan yang dimodelkan dalam bentuk Use Case Diagram ditunjukkan pada Gambar di bawah ini :

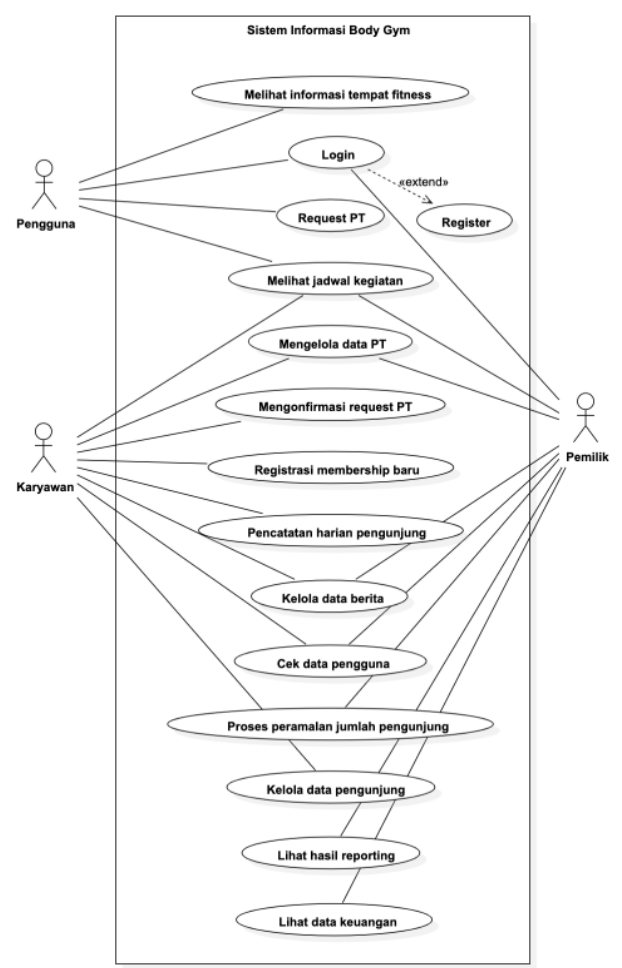

Gambar 1. Use Case Diagram

\subsection{Metode Pengolahan Data}

Pada penelitian ini, penulis menggunakan metode Double Exponential Smoothing untuk melakukan perhitungan peramalan jumlah pengunjung tempat fitness Body Gym. Metode exponential smoothing adalah metode pemulusan kurva distribusi dalam time series. Pada Double Exponential Smoothing datanya mempunyai pola tren. Kelebihan metode ini adalah dapat menggunakan data yang relatif sedikit, parameter yang digunakan lebih sedikit dan mudah dalam pengelolaan data dalam meramalkan (Pujiati, Yuniarti, \& Goejantoro, 2016). 
Gambar 2 menunjukkan alur dari perhitungan menggunakan metode Double Exponential Smoothing.

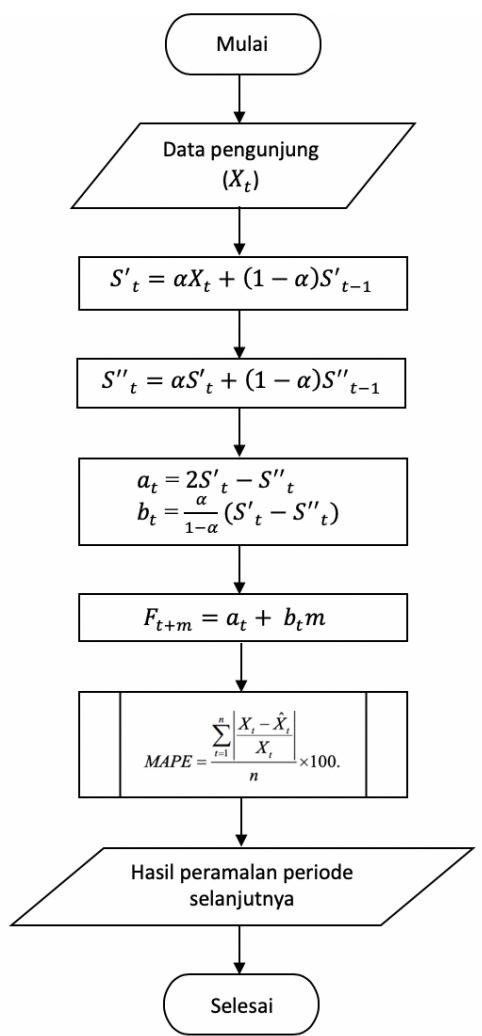

Gambar 2. Alur Perhitungan Metode Double Exponential Smoothing

Persamaan yang digunakan dalam implementasi Double Exponential Smoothing dengan metode Brown adalah :

Persamaan pemulusan tunggal (single) :

$S_{t}^{\prime}=\alpha X_{t}+(1-\alpha) S_{t-1}^{\prime}$

Persamaan pemulusan ganda (double) :

$S^{\prime \prime}{ }_{t}=\alpha X_{t}+(1-\alpha) S^{\prime \prime}{ }_{t-1}$

Nilai ramalan :

$F_{t+m}=\left(2 S^{\prime}{ }_{t}-S^{\prime \prime}{ }_{t}\right)+\left(\frac{\alpha}{1-\alpha}\left(S^{\prime}{ }_{t}-S^{\prime \prime}{ }_{t}\right)\right)$

Dengan keterangan :

$\alpha \quad=$ Konstanta pemulusan

$S^{\prime}{ }_{t}=$ Nilai pemulusan eksponensial tunggal

$S^{\prime \prime}{ }_{t} \quad=$ Nilai pemulusan eksponensial ganda

$m$ = jangka waktu maju ke depan.

$a_{t}, b_{t}=$ Parameter pemulusan eksponensial yang besarnya di antara $0-1$

$F_{t+m}=$ Hasil peramalan untuk periode ke depan yang diramalkan

Pada perhitungan ini, penulis menetapkan konstanta $(\alpha)$ sebesar 0,3 .
Langkah pertama adalah dengan menghitung hasil smoothing pertama menggunakan rumus sebagai berikut :

$$
S^{\prime}{ }_{t}=\alpha X_{t}+(1-\alpha) S^{\prime}{ }_{t-1}
$$

- Bulan Januari :

$$
S^{\prime}{ }_{1}=1501
$$

- Bulan Februari :

$$
\begin{aligned}
& S^{\prime}{ }_{2}=(0,3 \times 1382)+(1-0,3) \times 1501 \\
& S^{\prime}{ }_{2}=1465,30
\end{aligned}
$$

- Bulan Maret :

$$
S^{\prime}{ }_{3}=(0,3 \times 1611)+(1-0,3) \times
$$

1465,3

$S^{\prime}{ }_{3}=1509,01$

- Bulan April :

$$
\begin{aligned}
& S^{\prime}{ }_{4}=(0,3 \times 1371)+(1-0,3) \times \\
& 1509,01 \\
& S^{\prime}{ }_{4}=1467,61 \\
& . \quad{ }^{\circ} \text { Desember : } \\
& S^{\prime}{ }_{12}=(0,3 \times 1688)+(1-0,3) \times \\
& 1525,8 \\
& S^{\prime}{ }_{12}=1574,46
\end{aligned}
$$

- Bulan Desember :

Selanjutnya menghitung hasil smoothing kedua menggunakan rumus sebagai berikut:

$$
S_{t}^{\prime \prime}=\alpha S_{t}^{\prime}+(1-\alpha) S^{\prime \prime}{ }_{t-1}
$$

- Bulan Januari :

$$
S^{\prime \prime}{ }_{1}=1501
$$

- Bulan Februari :

$$
\begin{aligned}
& S^{\prime \prime}{ }_{2}=(0,3 \times 1465,3)+(1-0,3) \times \\
& 1501 \\
& S^{\prime \prime}{ }_{2}=1490,29
\end{aligned}
$$

- $\quad$ Bulan Maret :

$$
\begin{aligned}
& S_{3}^{\prime \prime}=(0,3 \times 1509,01)+(1-0,3) \times \\
& 1490,29 \\
& S_{3}^{\prime \prime}=1495,906
\end{aligned}
$$

- Bulan April :

$$
\begin{aligned}
& S^{\prime \prime}{ }_{4}=(0,3 \times 1467,61)+(1-0,3) \times \\
& 1490,29 \\
& S^{\prime \prime}{ }_{4}=1487,416
\end{aligned}
$$

- Bulan Desember :

$$
\begin{aligned}
& S^{\prime \prime}{ }_{12}=(0,3 \times 1574,461)+(1-0,3) \times \\
& 1481,74 \\
& S^{\prime \prime}{ }_{12}=1509,56
\end{aligned}
$$

Selanjutnya menentukan nilai parameter pemulusan menggunakan rumus sebagai berikut :

$$
a_{t}=2 S^{\prime}{ }_{t}-S^{\prime \prime}{ }_{t}
$$

- Bulan Januari :

$$
a_{1}=1501
$$

- Bulan Februari :

$$
a_{2}=2 \times 1456,3-1490,29=1140,31
$$


- Bulan Maret :

$$
\begin{array}{r}
a_{3}=2 \times 1509,01-1495,91 \\
=1522,114
\end{array}
$$

- Bulan April :

$$
\begin{array}{r}
a_{4}=2 \times 1467,607-1487,416 \\
=1447,798
\end{array}
$$

- Bulan Desember :

$$
\begin{array}{r}
a_{12}=2 \times 1574,461-1509559 \\
=1639,363
\end{array}
$$

Menentukan nilai trend linear menggunakan rumus sebagai berikut :

$$
b_{t}=\frac{\alpha}{1-\alpha}\left(S^{\prime}{ }_{t}-S^{\prime \prime}{ }_{t}\right)
$$

- Bulan Januari :

$$
b_{1}=0
$$

- Bulan Februari :

$$
\begin{gathered}
b_{2}=\frac{0,3}{1-0,3} \times(1465,3-1490,29) \\
=-10,71
\end{gathered}
$$

- Bulan Maret :

$$
b_{3}=\frac{0,3}{1-0,3} \times(1509,01-1495,906)
$$

- $\quad$ Bulan April :

$$
\begin{gathered}
b_{4}=\frac{0,3}{1-0,3} \times(1467,607-1487,416) \\
=-8,49
\end{gathered}
$$

- $\quad$ Bulan Desember :

$$
\begin{gathered}
b_{12}=\frac{0,3}{1-0,3} \times(1574,461-1509,559) \\
=27,815
\end{gathered}
$$

Menentukan nilai peramalan menggunakan rumus sebagai berikut :

$$
F_{t+m}=a_{t}+b_{t} m
$$

- Bulan Januari :

$$
F_{t+m}=1501
$$

- Bulan Februari :

$$
F_{t+m}=1440,31+(-10,71)=1429,6
$$

- Bulan Maret :

$$
F_{t+m}=1522,114+5,616=1527,73
$$

- Bulan April :

$$
\begin{array}{r}
F_{t+m}=1447,789+(-8,49) \\
=1439,308
\end{array}
$$

- Bulan Desember :

$$
F_{t+m}=1639,363+27,815=1667,178
$$

\section{Implementasi dan Pengujian}

Implementasi sistem pada sistem informasi peramalan pengunjung tempat fitness ini dilakukan dengan aplikasi berbasis website dengan bahasa pemrograman HTML, CSS, PHP dan database yang digunakan untuk membangun sistem adalah MySQL.

\subsection{Database} adalah :

Pada sistem ini terdapat 17 tabel, diantaranya
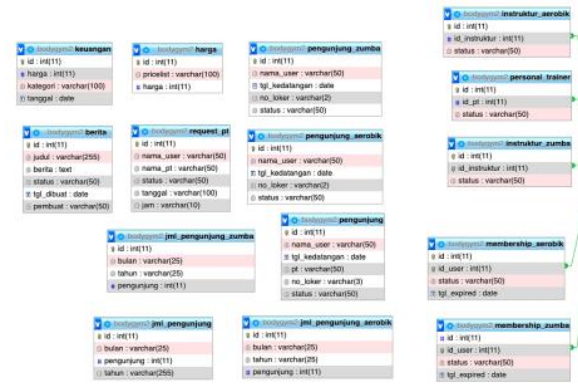

Gambar 3. Database Diagram

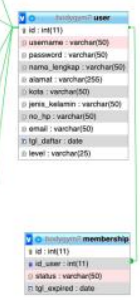

4.2 Tampilan Halaman Sistem

- Halaman Utama

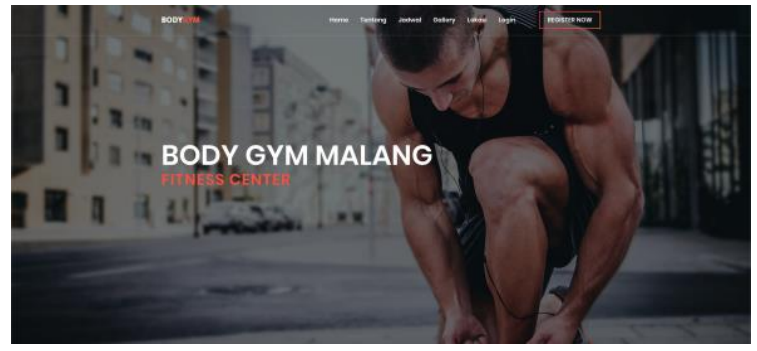

Gambar 4. Tampilan Halaman Utama

- Halaman Hasil Peramalan

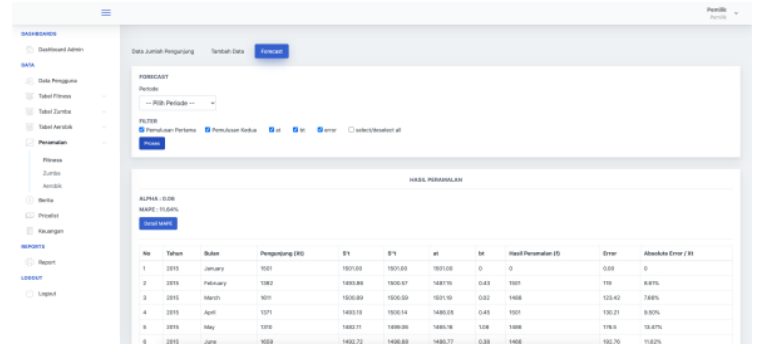

Gambar 5. Tampilan Hasil Peramalan

- Halaman Report

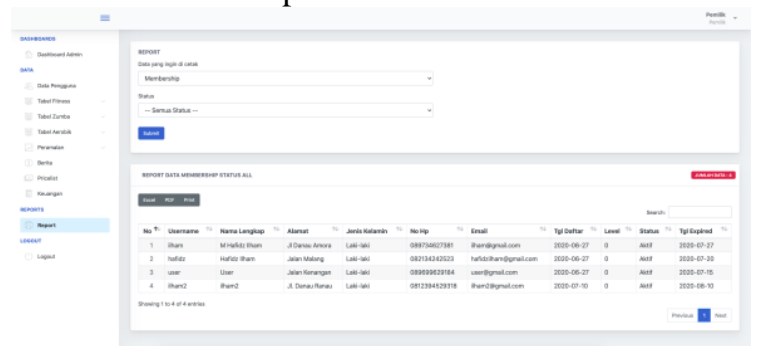

Gambar 6. Tampilan Reporting 


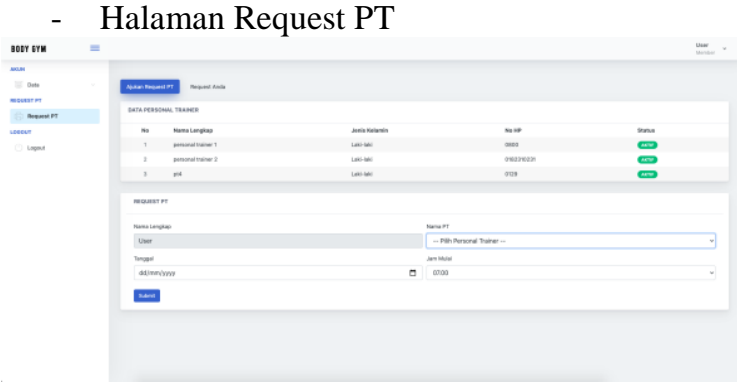

Gambar 7. Tampilan Request PT

- Halaman Rekomendasi Sistem

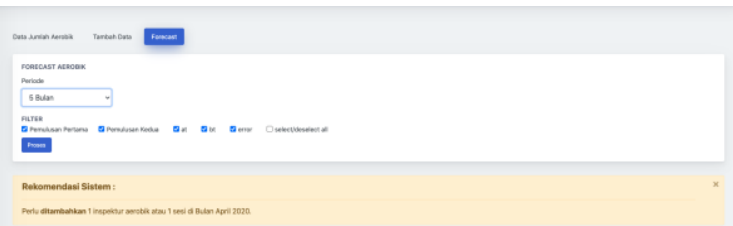

Gambar 8. Tampilan Rekomendasi Sistem

\section{Hasil dan Pembahasan :}

\subsection{Hasil Pengujian Sistem}

Kesimpulan yang didapatkan dari hasil pengujian Sistem Informasi Body Gym Kota Malang menggunakan metode black box dapat ditarik kesimpulan bahwa keluaran dari sistem ini sudah sesuai dengan fungsinya masing-masing.

\subsection{Hasil Pengujian User}

Kesimpulan dari para responden mengenai website ini setelah mencoba aplikasinya yaitu aplikasi ini dapat digunakan untuk para pengguna maupun member yang ingin menggali informasi mengenai Body Gym Kota Malang. Untuk kedepannya, diharapkan aplikasi ini dapat mendukung sepenuhnya untuk kegiatan sehari-hari para pekerja di Body Gym Kota Malang agar menjadi lebih efektif dan efisien.

\subsection{Hasil Peramalan}

Hasil peramalan yang didapatkan dari perhitungan dan pengujian akurasi jumlah pengunjung fitness untuk periode selanjutnya didapatkan hasil sebagai berikut :

Tabel 2. Tabel hasil peramalan jumlah pengunjung fitness

\begin{tabular}{|c|c|c|c|c|}
\hline No & Alpha & $\begin{array}{c}\text { Hasil } \\
\text { peramalan }\end{array}$ & $\begin{array}{c}\text { Error } \\
(\mathbf{\%})\end{array}$ & $\begin{array}{c}\text { Akurasi } \\
(\mathbf{\%})\end{array}$ \\
\hline 1 & 0,01 & 1652 & 13,46 & 86,54 \\
\hline $\mathbf{2}$ & $\mathbf{0 , 0 6}$ & $\mathbf{1 8 7 9}$ & $\mathbf{1 1 , 6 4}$ & $\mathbf{8 8 , 3 6}$ \\
\hline 3 & 0,11 & 1879 & 11,84 & 88,16 \\
\hline 4 & 0,16 & 1866 & 12,15 & 87,85 \\
\hline 5 & 0,21 & 1852 & 12,43 & 87,57 \\
\hline 6 & 0,26 & 1839 & 12,70 & 87,30 \\
\hline 7 & 0,31 & 1830 & 12,91 & 87,09 \\
\hline 8 & 0,36 & 1821 & 13,13 & 86,87 \\
\hline
\end{tabular}

\begin{tabular}{|c|c|c|c|c|}
\hline No & Alpha & $\begin{array}{c}\text { Hasil } \\
\text { peramalan }\end{array}$ & $\begin{array}{c}\text { Error } \\
(\boldsymbol{\%})\end{array}$ & $\begin{array}{c}\text { Akurasi } \\
(\boldsymbol{\%})\end{array}$ \\
\hline 9 & 0,41 & 1813 & 13,31 & 86,69 \\
\hline 10 & 0,46 & 1808 & 13,58 & 86,42 \\
\hline 11 & 0,51 & 1807 & 13,90 & 86,10 \\
\hline 12 & 0,56 & 1811 & 14,27 & 85,73 \\
\hline 13 & 0,61 & 1820 & 14,68 & 85,32 \\
\hline 14 & 0,66 & 1836 & 15,10 & 84,90 \\
\hline 15 & 0,71 & 1859 & 15,56 & 84,44 \\
\hline 16 & 0,76 & 1890 & 16,06 & 83,94 \\
\hline 17 & 0,81 & 1929 & 16,60 & 83,40 \\
\hline 18 & 0,86 & 1978 & 17,16 & 82,84 \\
\hline 19 & 0,91 & 2036 & 17,79 & 82,21 \\
\hline 20 & 0,96 & 2105 & 18,53 & 81,47 \\
\hline
\end{tabular}

Penilaian pengujian kesalahan menggunakan metode MAPE, dari nilai konstanta antara 0 - 1, nilai konstanta yang digunakan untuk perhitungan peramalan adalah yang menghasilkan nilai MAPE yang terendah. Berdasarkan hasil perhitungan dan pengujian akurasi jumlah pengunjung fitness pada konstanta 0,06 menunjukkan hasil yang paling baik, dikarenakan konstanta tersebut memiliki tingkat error yang paling rendah dan memiliki tingkat akurasi yang paling baik diantara konstanta yang lainnya.

\section{Kesimpulan dan Saran : \\ 6.1 Kesimpulan}

Dari hasil penelitian yang telah dilakukan pada Sistem Informasi Body Gym Kota Malang dengan Peramalan Jumlah Pen gunjung Menggunakan Metode Double Exponential Smoothing, dapat diambil kesimpulan sebagai berikut :

1. Sistem ini dapat melakukan proses pendataan pengunjung dan kegiatan pendukung setiap harinya secara terkomputerisasi.

2. Sistem dapat melakukan pengolahan data Body Gym sehari-hari dengan komputerisasi dan secara online.

3. Sistem dapat mengimplementasikan Metode Double Exponential Smoothing untuk meramalkan jumlah pengunjung Body Gym untuk memprediksi jumlah pengunjung di periode mendatang. Menggunakan alpha 0,06 menghasilkan peramalan sejumlah 1879 pengunjung di periode selanjutnya dengan error $11,64 \%$ dan memiliki akurasi sebesar $88,36 \%$.

\subsection{Saran}

Sistem informasi Body Gym yang dibangun dapat dikembangkan lagi lebih lanjut sebagai berikut:

1. Perlu ditambahkan lagi fitur real-time untuk pengunjung tempat Gym.

2. Perlu ditambahkan fitur pembayaran online yang terintegrasi dan pencetakan kwitansi.

3. Perlu dicoba menggunakan metode peramalan yang lain seperti metode Multiple Regression (regresi berganda) 
agar hasilnya dapat lebih akurat lagi dikarenakan metode tersebut memiliki lebih dari satu variabel bebas.

\section{Daftar Pustaka :}

Fatimah. (2015). Perbandingan Keefektifan Metode Exponential Smoothing dan Metode Dekomposisi untuk Peramalan Tingkat Hunian Hotel Al Salam II Sengkang.

Fifi Ericawati, R. A. (2017). Penerapan Metode Double Exponential Smoothing pada Peramalan Produksi Tanaman Pangan. Malang.

Fitri, K. U., \& Fatmawati, A. (2019). Sistem Informasi Pelanggan pada Bengkel Marno Jaya Motor.

Ginting, R., \& Suryadi, L. (2018). RANCANGAN SISTEM INFORMASI ADMINISTRASI FITNESS DENGAN METODOLOGI BERORIENTASI OBYEK. Jakarta.

Gordon, B. D. (1991). Kerangka Dasar Sistem Informasi Manajemen Bagian 1. Jakarta: PT. Pustaka Binamas Pressindo.

Hermawan, A. W., \& Purwanto, H. L. (2019). Penerapan Metode Double Exponential Smoothing untuk Prediksi Tingkat Kepadatan Pengiriman Barang. Malang.

Imbar, R. V., \& Andreas, Y. (2010). Sistem Informasi Toko Listrik Aryono King dengan Peramalan Stok Barang menggunakan Metode Double Exponential Smoothing. Bandung.

Perdana, F. R., Daryanto, \& Wahyu, H. (2015). Perbandingan Metode Double Exponential Smoothing dan Triple Exponential Smoothing pada Peramalan Penjualan Rokok.

Pratama, D. A. (2016). Aplikasi Metode Double Exponential Smoothing Brown dan Holt untuk Meramalkan Total Pendapatan Bea dan Cukai.

Pujiati, E., Yuniarti, D., \& Goejantoro, R. (2016). Peramalan Dengan Menggunakan Metode Double Exponential Smoothing Dari Brown. Samarinda.

Rahayu, I. M., \& Amrozi, Y. (2019). Perancangan Sistem Informasi Fasilitas Fitness Center Berbasis Web di Universitas Islam Negeri Sunan Ampel.

Rubiati, N. (2018). Aplikasi Informasi Pelayanan Fitness pada Golden Fitness Center Dumai dengan Bahasa Pemrograman PHP. Riau.

Sari, \& Nita Zilviah. (2018). FORECASTING MODAL SENDIRI, MODAL PINJAMAN, DAN SHU (SISA HASIL USAHA) PADA KOPERASI GANESA STUDI GRUP SINGARAJA TAHUN 2018.

Sitepu, R., Bangun, P. B., \& Suryansyah, M. (2013). Penggunaan Metode Deseasonalized untuk Meramalkan Jumlah Pengunjung Objek WIsata Danau Ranau, Sumatera Selatan.
Supranto, J. (2008). Statistik Teori dan Aplikasi. Jakarta: Erlangga.

Sutabri, T. (2005). Sistem Informasi Manajemen. Yogyakarta: Andi. 